\title{
The University of Manchester
}

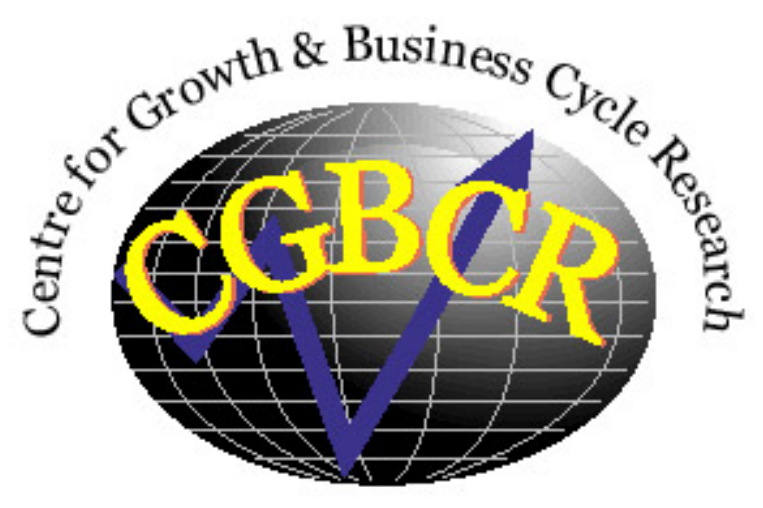

Discussion Paper Series

\section{Dating the Business Cycle in Britain}

\author{
By \\ Michael Artis \\ EUI, Florence, Italy, University of Manchester and CEPR
}

September 2002

Number 017

\section{Download paper from:}

http://www.ses.man.ac.uk/cgbcr/discussi.htm

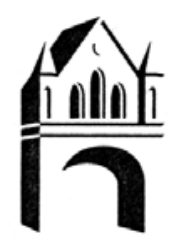




\title{
Dating the Business Cycle in Britain
}

\author{
Michael Artis $^{H}$ \\ EUI, Florence, University of Manchester and CEPR.
}

\section{Introduction}

The intention in this paper is to provide a dating of the business cycle in Britain using the National Institute's (see Salazar et al., 1997) innovative series of monthly GDP as a base. In the usual way analysts will describe the cycle as a recurrent - but not strictly periodic - oscillation in the general level of economic activity. The latter term, in turn, is taken to betoken that a business cycle is pervasive. Gross Domestic Product is widely accepted as the best measure we can think of to represent the general level of economic activity and it is generally assumed that the measure takes adequate account of the "pervasiveness" that is required in the definition of the cycle. This being so, most business cycle studies nowadays proceed at the quarterly or national level, as the availability of GDP data allows. For dating purposes, however, even the quarterly frequency is rather coarse; for a given "true" incidence of peak or trough in a given month, the corresponding registration of that peak or trough in quarterly data can easily slip by a quarter. A true peak-incidence in, say, March, may easily not show up until Quarter 2, thus not making it distinct from, say, June. This is rather unsatisfactory and analysts have tried to track the business cycle at a higher frequency in one of two alternative ways. One way is simply to use the data on industrial production which are, quite frequently, available at a monthly frequency (see e.g., Artis et al, 1997: Artis and Toro, 2000). The are at least two problems with this: industrial production is a declining and, in the UK now, quite small proportion of overall economic activity as measured by GDP; second, the series is very noisy, making it sometimes difficult to turn the higher frequency of availability to good advantage. A second approach, practised by the analysts at the Economic Cyclical

\footnotetext{
${ }^{\mathrm{H}}$ The author is grateful to Ekaterina Vostroknoutova for research assistance and to Tommaso Proietti for his $\mathrm{BB}(\mathrm{M})$ programs.
} 
Research Institute (ECRI: http://www.businesscycle.com/) is to use data on a variety of series available at the monthly level in an endeavour to be guided by them to a consensus on turning points for the general level of economic activity. In this respect they are following in the footsteps of the NBER "founding fathers" of business cycle analysis - analysts like Burns, Mitchell and Moore. It will be natural for us to compare our dating chronology with ECRI's.

In fact we shall produce two chronologies, not just one. The terminology of "the business cycle" belongs strictly to that of the so-called "classical cycle", where peaks (and troughs) and marked by subsequent absolute declines (increases) in the chosen measure of economic activity. But there is also the concept of the "growth" or "deviation" cycle, where peaks (and troughs) are essentially marked by upward (downward) inflections in the growth rate of the chosen measure of economic activity. This latter concept of the cycle involves some form of de-trending, where a number of papers (e.g., Canova 1995, Osborn 1995 are examples) have shown that there exist substantial pitfalls awaiting the unwary. Even whilst avoiding the most obvious of these pitfalls it must immediately be obvious that the objective of precision in dating will be compromised by the smoothing involved in the de-trending.

In what follows, we begin in the next section by discussing the construction of the monthly GDP series as it is described in the relevant paper (Salazar et al, 1997), and its suitability for our purpose. In section 3 we discuss the concept of the classical cycle and the algorithm we apply to dating it in the monthly GDP series. We then discuss some pertinent aspects of the results and compare the dating we obtain with that obtained by ECRI, also at a monthly level: more tentatively, we also compare our chronology with the dates proposed for quarterly GDP in Krolzig and Toro (2001). In section 4 we turn to the concept of the growth or deviation cycle, again comparing our results with those of ECRI and, more tentatively, those of Krolzig and Toro.

\section{Monthly GDP}

Our basic data series, of monthly GDP, were supplied by the National Insitute of Economic and Social Research and cover the period from January 1974 to February 2002 , on a seasonally adjusted basis. The method of construction of the data relies heavily on the use of a technique analogous to the well-known "Chow-Lin" (1971) 
method of interpolating data from related series to the one in question. Somewhat more than $75 \%$ of the (output) series making up GDP are interpolated this way, which involves the use of genuinely monthly data to this extent. The remainder, slightly less than a quarter of the total, is simply interpolated from quarterly series on the output components involved - agriculture and non-marketed (public) services - and does not represent the use of data points observed at the monthly level. The proportion of the total based on genuine monthly inputs should be great enough, to make the objective of a monthly dating of the cycle one that is within reach. The data are split into five components altogether: agriculture (1.9\%), industrial production (27.8\%), construction (7.2\%), marketed (private sector) services (41.9\%) and non-marketed (public sector) services (21.2\%): the percentage shares are the weights with which the components are combined to yield total GDP.

As will be demonstrated below, industrial production is among the more cyclical of these components. However, the fact that the main other component series are less noisy in general has the advantage that the overall GDP series is less noisy than that of industrial production alone. Correspondingly, the need to smooth the series prior to identifying the turning points should be less pressing and the subsequent identification procedure should be less plagued by problems of "smearing" that arise when smoothing is heavy and there is consequently considerable uncertainty about the exact timing of events.

\section{The Classical Cycle}

The concept of the classical cycle has recently reclaimed a degree of popularity. Dating the peak of the cycle by reference to a subsequent absolute decline in output no longer seems such a "rare event" activity as it did before the first oil shock; moreover, the intervening popularity of the growth cycle has suffered from the realization that detrending techniques may spuriously create cycles of their own and shift the timing of the turning points in undesirable ways.

The demands of a classical cycle dating algorithm are relatively few: first, peaks are to be defined by reference to an immediate subsequent downturn in the absolute level of output and troughs by immediate recovery in the level of output. Then, peaks and troughs are required to alternate; finally, to qualify as cycle phases the downturns and 
upturns are required to fulfil minimum duration requirements: here 5 months in each case, whilst the cycle as a whole will only be identified as such provided that it lasts for 15 months or more. These criteria have been inherited from the computer algorithm devised by Bry and Boschan (1971) to mimic for a univariate series the identification procedures implemented by the NBER in its cycle dating procedures. Subsequently, the Bry-Boschan (BB) algorithm has also been adapted for data at the quarterly frequency (as in Pagan (2002) for example), whilst eliminating some of the steps suggested in the original. Using the methodology of the Markov chain, it can be shown how the various restrictions listed here can be enforced (and how they can be supplemented by additional restrictions on amplitude if desired): see Appendix A to Artis et al. (2002).

The remaining issue is then to decide to what transformation of the data (if any) the dating algorithm should be applied. For example, it would seem desirable to eliminate seasonal fluctuations, and possibly what appear to be outlier observations (preferably, where these can be identified with a causal event, like a strike, or a bad harvest). This removes the possibility of confusing cyclical with merely seasonal fluctuation, or confounding the reaction to a strike with a cyclical phenomenon. No sooner are these things said than some cautions come to mind: for example, some cyclical phenomena are plainly initiated by shocks that might look like outliers at the time, whilst the difficulties of detecting and removing seasonality are well-known. Here, although the original data are in principle seasonally adjusted, experiment suggested that a mild degree of smoothing would be advisable; the HP filter (Hodrick and Prescott, 1997), with $\lambda=0.52$ being applied for this purpose. ${ }^{1}$

Figure 1 shows the original series, the filtered series and the dates of the troughs and peaks selected. When the dating algorithm was applied to the raw data series, many more cycles were identified - fully twice as many. A glance at the Figure will show the reader why and should convince her that a degree of smoothing is needed. The procedure leading to the identification of the turning points in GDP can easily be replicated for the component series and the "stylized facts" (Pagan, 2002) calculated: these results are shown in Table 1. The display prompts a number of observations. 
Virtually three complete cycles in GDP are detected in the period. They are highly asymmetrical, as should be expected of a growth economy - the average amount of time spent in the expansion phase (that is, from trough to peak) is nearly seven times as large as the amount of time spent in recession (that is from peak to trough) - as indicated by the average probability statistics shown in the third and fourth rows of the table. The same asymmetry is again expressed in the difference between the average monthly duration of expansions (row 5) and the average monthly duration of recessions (row 6). Amplitude is measured as the average of the percentage increase in GDP in expansion and (decline in) recession phases, whilst "steepness" is the quotient of the amplitude and duration. It can be seen that the two phases are in fact about equally steep, the larger expansion amplitudes being offset by their greater duration. A notable feature is the unusually long expansion phase that set in after the last identified trough, some ten years ago. All the calculations can be replicated for components of GDP, as shown in the table. It is noticeable that construction and industrial production are about equally cyclical, judged by the number of cycles identified in the period, and are much more cyclical than the service sectors or GDP as a whole. Interestingly, agriculture is shown as the most cyclical of all sectors; but this sector is of little importance in the make-up of GDP as a whole in the UK and the monthly series is purely interpolated from quarterly data.

\section{[Table 1 and Figure 1 hereabouts]}

Because the Economic Cyclical Research Institute (ECRI) has been producing monthly turning points in the UK classical cycle for some time now, without benefit of the NIESR's monthly GDP, it is interesting to compare the ECRI chronology with our own. ECRI's procedures depend on their identification of a coincident indicator series; their description of their dating procedure can be quoted from their website as follows:

"In line with the procedure used to determine the official U.S. recession and expansion dates, the business cycle peak and trough dates for each country are chosen on the basis of the best consensus among the dates of

\footnotetext{
${ }^{1}$ The data are in principle already seasonally adjusted at source; the idea is simply to remove outliers and any excess seasonality that may remain.
} 
the turning points in the coincident index and its components, i.e., the key measures of output, income, employment and sales.”

The comparison of the dates identified by ECRI and ourselves is given in Table 2 . This shows in general quite a good correspondence. The same number of cycles is identified in the period in question and the turning points identified are generally within three months of each other (and in one case coincident). Only the dating of the last trough is more discrepant (with a difference of seven months). It is noticeable that, with the exception of the one coincident dating, our dating tends to lead ECRI's. It is conceivable - though this can only remain a speculation in the absence of more detailed knowledge of ECRI's procedures - that the reason for this is that employment is counted by ECRI among the components of the coincident indicator, whereas it is known to lag output. More generally, the chronologies should be noted as encouragingly similar. A comparison with the chronology suggested by Krolzig and Toro (2001 offers less close correspondence: the Krolzig-Toro dating is carried out on quarterly GDP, and five cycles are identified over the period for which we have selected only three. Those three, however, find a close correspondence with the Krolzig-Toro dates ${ }^{2}$.

[Table 2 hereabouts]

\section{The deviation cycle}

The deviation or growth cycle takes off from a definition of the upper turning point as one which is marked by a decline in the growth rate, with the lower turning point symmetrically defined as being marked by an increase in the growth rate. Such a definition could lead to a peak (trough) being identified even when the observation in question was "below (above) trend" and needs to be supplemented to avoid this contingency: alternatively we can define a cycle as a growth rate cycle in the absence of the additional stipulation about the relative level of the growth rate variable. Again, as with the classical cycle, it is standard to specify minimum duration restrictions both for the individual phases and for the cycle as a whole (here, 5, 5 and 7 months respectively). It is the growth or deviation cycle that has occupied centre 
stage in post war business cycle studies until recently and analysts have used many different methods for de-trending or filtering the series. The most popular in recent years have been the Hodrick-Prescott filter (Hodrick and Prescott, 1997) and the Baxter-King filter (Baxter and King 1999). The H-P filter is normally treated as a variant on the linear filter in which the user is able to allow for a flexible trend to appear by setting the dampening parameter $\lambda$ at an appropriate value (e.g. Ravn and Uhlig 1997). The Baxter-King filter - or almost-ideal band-pass filter - has gained in popularity recently perhaps because it promises to be less arbitrary. The filter relies on eliminating frequencies higher and lower than those pertaining to the business cycle and only some assumption needs to be made about what those are, where there is a high degree of agreement that "the cycle" is around 1.5 to 8 or 10 years in length. The method of computation, however, involves a relatively severe loss of data points at either end of the sample; sometimes this can be made good by relying on forecast data to supplement the sample. However, as explained at greater length in Artis et al (2002), the Baxter-King filter can be closely replicated by using the difference between two H-P filters, the relevant values of $\lambda$ being chosen to isolate to periodicities between (here) 15 and 96 months $^{3}$. The resultant series contains just the business cycle periodicities that we wish to entertain. Figure 2 shows the H-P bandpass filtered series. The dating algorithm is applied to the transformed series to detect the turning points and characteristics of the cycles identified. The turning point dates and the resultant "stylized facts" are shown, respectively, in Figure 2 and Table 3; again the procedure has been mechanically replicated for the component series on monthly GDP.

[Figure 2 and Table 3 hereabouts]

The table shows a number of items of interest. First, the number of cycles identified is larger than in the case of the classical cycle - about twice as many in this sample period. Second, the data shown on the relative frequency, duration and amplitude now indicate a high degree of symmetry in the cycles identified, as opposed to the

\footnotetext{
${ }^{2}$ The dates of peaks identified by Krolzig and Toro in the period covered by the present study are: Q3, 74; Q4, 76; Q2, 79; Q1 84,; Q2, 80. For troughs the dates are: Q3, 75; Q3, 77; Q2, 81; Q3, 84; Q2, 92.

${ }^{3}$ Kaiser and Maravall (1999) show how the H-P filter can be treated as a low pass filter, leading to the idea of a subtraction of one from another as a band-pass filter.
} 
case with the classical cycle. Figure 2 suggests a trend towards diminishing volatility, or declining amplitude, in the cycle. A comparison with the identification made by ECRI is given in Table 4: however, it should be noted immediately that the ECRI growth cycle is in fact defined as a growth rate cycle, and this may have led to some of the discrepancies between the dating suggested in this paper and theirs. At any rate, the correspondence is less than we saw in the case of the classical cycle; even so, of the nine peaks identified in this paper, no less than four appear in the ECRI chronology within a month or at the same time; of the eight troughs identified, four appear in the ECRI chronology within two months of the dates identified here. Still, there is plainly a certain amount of disagreement. Krolzig and Toro (2001) do not provide a deviation cycle dating, and whilst there are many papers dealing with the growth cycle on quarterly and annual UK data (Artis, Marcellino and Proietti (2002) is a recent example), not many provide a chronology of turning points; at the same time, the methods of detrending used differ considerably as do the data vintages and frequencies used, so that it appeared comparatively uninformative to attempt further comparisons here.

[Table 4 hereabouts]

\section{Conclusions}

The UK monthly GDP series is unique in representing a carefully constructed estimate of GDP at a high frequency. Sufficient genuine monthly information is incorporated in the estimate to make it reasonable to choose it as the monthly proxy for the general level of economic activity on which cyclical analysis is focussed. However, this is not the end of the matter. In order to use the series for the identification of cyclical turning points a dating algorithm is needed and some degree of smoothing appears necessary. The algorithm will contain restrictions to ensure that it is a cycle which is being identified and not some other more short-lived phenomenon; smoothing performs a similar function ${ }^{4}$. These stages involve judgment and discretion, even if they are ultimately written down as "rules". Matters become more complicated when it is desired to investigate the growth or deviation cycle. The particular selections made in the rules used in this paper to isolate the classical cycle 
turn out to produce results quite close (but generally with a short lead) to those already established by ECRI, which embodies the NBER tradition in business cycle dating. For the case of the deviation cycle the correspondence is not so close, as, in general might be expected.

\section{References}

Artis, M.J., and J. Toro (2000) "Testing for Common Patterns in European Business Cycle Chronologies", Greek Economic Review, 20, 77-92, Autumn.

Artis, M.J., M. Marcellino, and T. Proietti (2002) "Dating the Euro Area Business Cycle", mimeo, EUI, Florence, September.

Artis, M.J., Z, Kontomelis, and D.R. Osborn (1997) "Business Cycles for G7 and European Countries, Journal of Business, 70, 249-279.

Baxter, M. and R.G. King (1999) "Measuring Business Cycles: approximate bandpass filters for Economic Time Series", Review of Economics and Statistics, 81, 57593.

Bry, G. and C. Boschan (1971) "Cyclical Aspects of Time Series: Selected Procedures and Computer Programs", National Bureue of Economic Research, Technical Paper No 20.

Canova, F (1998) "De-Trending and Business Cycle Facts", Journal of Monetary Economics, 41, 475-512.

Chow, G.C. and A.L. Lin (1971) "Best linear unbiased interpolation, distribution and extrapolation of time series by related series", Review of Economics and Statistics, 53, $372-75$.

Hodrick, R.J. and E.C. Prescott (1997) "Post-war US Business Cycles: an Empirical Investigation", Journal of Money, Credit and Banking, 29, 1-16.

Kaiser, R. and A. Maravall (1999) "Estimation of the business cycle: a modified Hodrick-Prescott filter "Madrid: Banco de Espana, 1999.

\footnotetext{
${ }^{4}$ Although not demonstrated here, in related work (Artis et al 2002) it has been found that "light" smoothing is a good subsitute for restrictions on amplitude.
} 
Krolzig, H.-M. and Toro, J. (2001). "Classical and Modern Business Cycle Measurement: The European Case", University of Oxford, Discussion Papers in Economics, 60.

Osborn, D.R. (1995). "Moving average detrending and the analysis of business cycles", Oxford Bulletin of Economics and Statistics, 57, 547-58.

Pagan, A. (2002), Lectures on the Business Cycle, mimeo, EUI, Florence, April.

Ravn, M.O. and H. Uhlig, (1997) On adjusting the HP-filter for the frequency of observations, CEnter Discussion Papers, 50.

Salazar, E., R. Smith, M. Weale, and S. Wright (1997), “A Monthly Indicator of GDP”, National Institute Economic Review, 161, July, 84-90. 
Table 1. The Classical Cycle: Cycle characteristics, UK monthly GDP series.

\begin{tabular}{|l|c|c|c|c|c|c|}
\hline \multicolumn{1}{|c|}{ Components } & Industry & $\begin{array}{c}\text { Agricult } \\
\text { ure }\end{array}$ & $\begin{array}{c}\text { Construc } \\
\text { tion }\end{array}$ & $\begin{array}{c}\text { Private } \\
\text { Services }\end{array}$ & $\begin{array}{c}\text { Public } \\
\text { Services }\end{array}$ & GDP \\
\hline $\begin{array}{l}\text { Number of cycles } \\
\text { P-P: }\end{array}$ & 7 & 11 & 7 & 4 & 2 & 3 \\
\hline $\begin{array}{l}\text { Number of cycles } \\
\text { T-T: }\end{array}$ & 6 & 10 & 8 & 4 & 2 & 3 \\
\hline $\begin{array}{l}\text { Average Expansion } \\
\text { Probability: }\end{array}$ & 0.73 & 0.51 & 0.56 & 0.83 & 0.89 & 0.85 \\
\hline $\begin{array}{l}\text { Average Recession } \\
\text { Probability: }\end{array}$ & 0.25 & 0.47 & 0.43 & 0.16 & 0.11 & 0.14 \\
\hline $\begin{array}{l}\text { Average Duration } \\
\text { of Expansions: }\end{array}$ & 35.39 & 15.79 & 26.86 & 70.18 & 149.87 & 95.91 \\
\hline $\begin{array}{l}\text { Average Duration } \\
\text { of Recessions: }\end{array}$ & 14.33 & 15.80 & 18.00 & 13.50 & 18.00 & 15.67 \\
\hline $\begin{array}{l}\text { Average Amplitude } \\
\text { of Expansions: }\end{array}$ & 0.11 & 0.10 & 0.13 & 0.25 & 0.23 & 0.23 \\
\hline $\begin{array}{l}\text { Average Amplitude } \\
\text { of Recessions: }\end{array}$ & -0.076 & -0.087 & -0.075 & -0.025 & -0.014 & -0.036 \\
\hline $\begin{array}{l}\text { Steepness of } \\
\text { expansions: }\end{array}$ & 0.003 & 0.006 & 0.005 & 0.003 & 0.001 & 0.002 \\
\hline $\begin{array}{l}\text { Steepness of } \\
\text { recessions: }\end{array}$ & -0.005 & -0.005 & -0.004 & -0.002 & -0.001 & -0.002 \\
\hline
\end{tabular}

Note: Seasonally adjusted monthly series were additonally smoothed with

Butterworth Filter $\left(2,1.25^{*} 12\right)$, and then the dating algortihm was applied (BBM).

Table 2: Comparative dating of the classical cycle

\begin{tabular}{|l|l|l|l|}
\hline \multicolumn{2}{|c|}{ ECRI } & \multicolumn{2}{c|}{ This paper } \\
\hline Peaks & \multicolumn{1}{|c|}{ Troughs } & \multicolumn{1}{c|}{ Peaks } & Troughs \\
\hline Sept 74 & Aug 75 & July 74 & May 75 \\
\hline June 79 & May 81 & June 79 & Feb 81 \\
\hline May 90 & Mar 92 & Mar 90 & Aug 91 \\
\hline
\end{tabular}


Table 3 Characteristics of the deviation cycle in UK monthly GDP

\begin{tabular}{|l|c|c|c|c|c|c|}
\hline Series: & Industry & $\begin{array}{l}\text { Agricult } \\
\text { ure }\end{array}$ & $\begin{array}{l}\text { Construc } \\
\text { tion }\end{array}$ & $\begin{array}{l}\text { Private } \\
\text { Services }\end{array}$ & $\begin{array}{l}\text { Public } \\
\text { Services }\end{array}$ & GDP \\
\hline $\begin{array}{l}\text { Number of cycles } \\
\text { P-P: }\end{array}$ & 7 & 10 & 7 & 7 & 7 & 9 \\
\hline $\begin{array}{l}\text { Number of cycles } \\
\text { T-T: }\end{array}$ & 7 & 9 & 7 & 6 & 8 & 0.57 \\
\hline $\begin{array}{l}\text { Average Expansion } \\
\text { Probability: }\end{array}$ & 0.54 & 0.51 & 0.53 & 0.59 & 0.60 & 0.40 \\
\hline $\begin{array}{l}\text { Average Recession } \\
\text { Probability: }\end{array}$ & 0.46 & 0.49 & 0.47 & 0.41 & 0.40 \\
\hline $\begin{array}{l}\text { Average Duration } \\
\text { of Expansions: }\end{array}$ & 26.29 & 17.10 & 25.57 & 28.43 & 29.00 & 21.33 \\
\hline $\begin{array}{l}\text { Average Duration } \\
\text { of Recessions: }\end{array}$ & 22 & 18.56 & 22.71 & 23.17 & 16.87 & 18.25 \\
\hline $\begin{array}{l}\text { Average Amplitude } \\
\text { of Expansions: }\end{array}$ & 0.06 & 0.07 & 0.07 & 0.03 & 0.01 & 0.02 \\
\hline $\begin{array}{l}\text { Average Amplitude } \\
\text { of Recessions: }\end{array}$ & -0.06 & -0.08 & -0.08 & -0.03 & -0.01 & -0.02 \\
\hline $\begin{array}{l}\text { Steepness of } \\
\text { expansions: }\end{array}$ & 0.002 & 0.004 & 0.004 & 0.001 & 0.0005 & 0.001 \\
\hline $\begin{array}{l}\text { Steepness of } \\
\text { recessions: }\end{array}$ & -0.003 & -0.004 & -0.004 & -0.001 & -0.001 & -0.001 \\
\hline
\end{tabular}

Note: Seasonally adjusted monthly series were smoothed with the HP Bandpass filter $\left(p_{1}=1.25^{*} 12\right.$; i.e. lower bc period 15 months, $p_{2}=8 * 12$, i.e. upper bc period 8 years; $l a m b d a_{1}=33.4476$, lambda $\left._{2}=.54535\right)$. No threshold was used. Then, a monthly dating algorithm BCDatingMDevCycle was applied, based on BBM.

Table 4. Comparative Dating of the Deviation Cycle

\begin{tabular}{|l|l|l|l|}
\hline \multicolumn{2}{|c|}{ ECRI } & \multicolumn{2}{c|}{ This Paper } \\
\hline Peak & \multicolumn{1}{|c|}{ Trough } & \multicolumn{1}{|c|}{ Peak } & Trough \\
\hline Jan 73 & May 75 & July 74 & June 75 \\
\hline July76 & Apr 77 & Jan 77 & June77 \\
\hline June 79 & May 80 & May 79 & Mar 81 \\
\hline Oct 83 & Aug 84 & Oct 83 & Aug 84 \\
\hline May 85 & Dec 85 & Apr 85 & Feb 86 \\
\hline Jan 88 & Apr 91 & Sept 88 & June 92 \\
\hline July 94 & Aug 95 & Sept 94 & July 96 \\
\hline July 97 & Feb 99 & Apr 98 & Mar 99 \\
\hline Jan 00 & & Oct 00 & \\
\hline
\end{tabular}


Figure 1. Turning Points in the Classical Cycle

Monthly GDP and the H-P filter; peaks and troughs

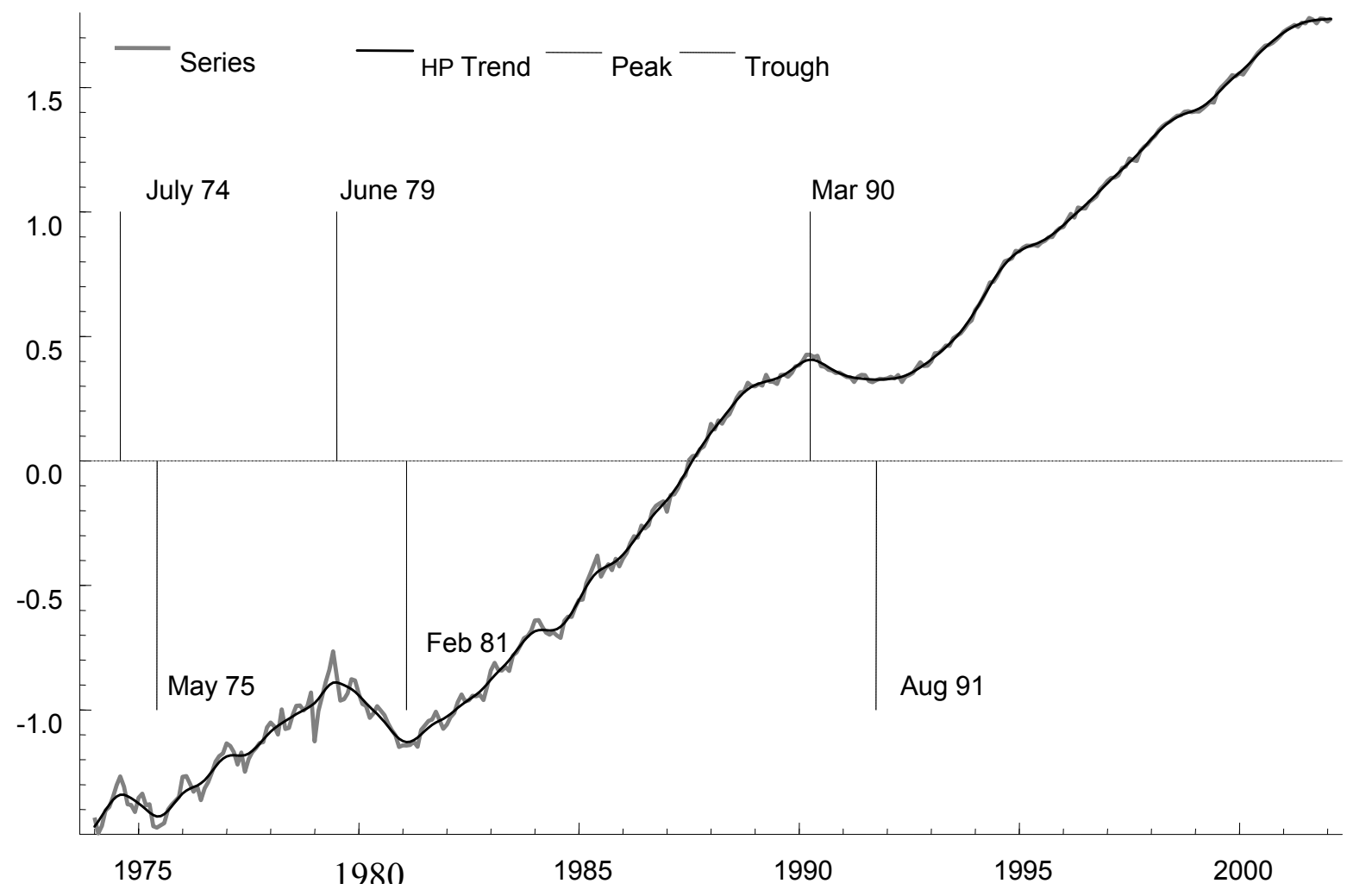


Figure 2. Turning Points in the Deviation Cycle

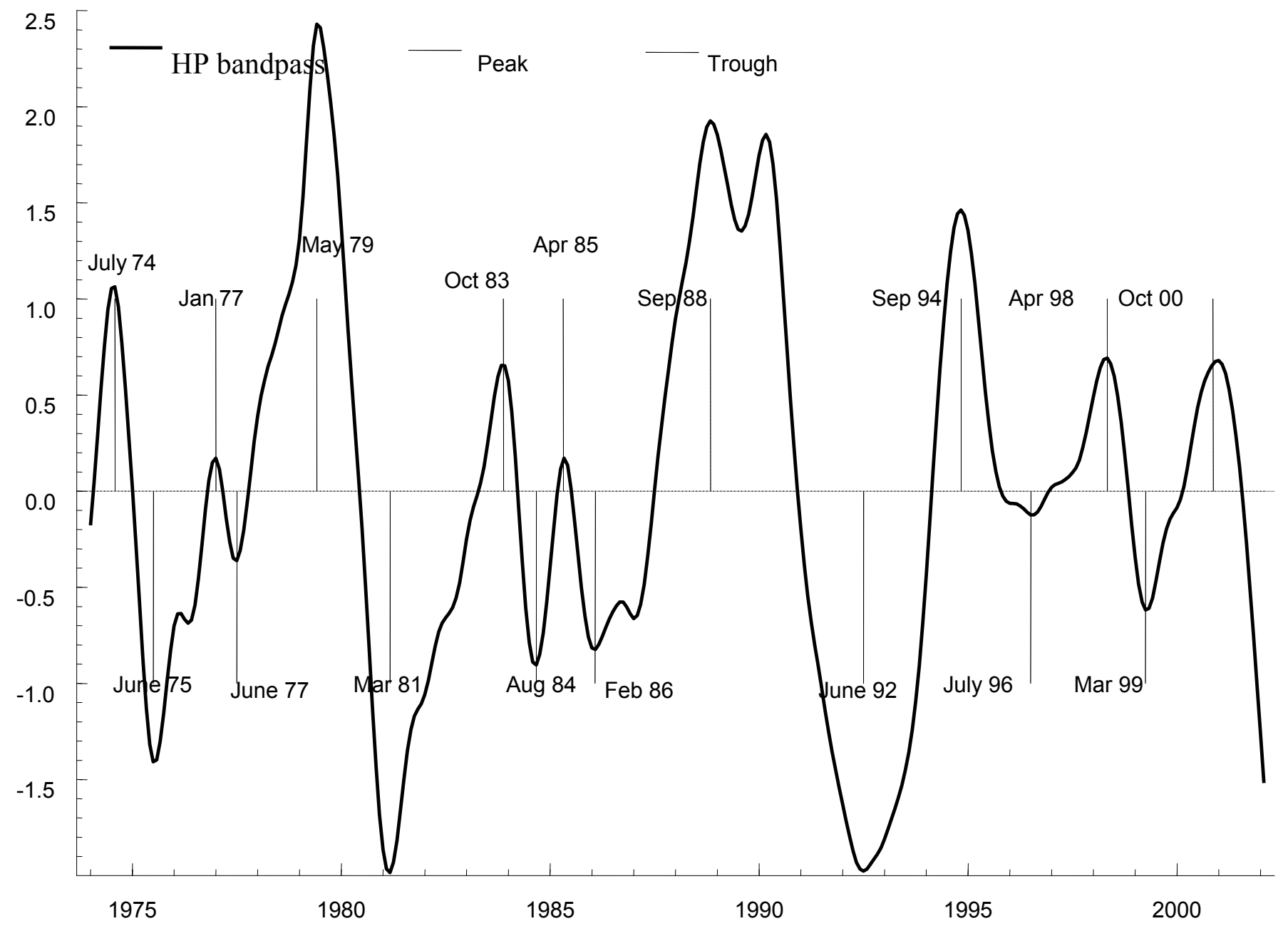

